\title{
Treatment Strategies and Prognosis of Patients With Synchronous or Metachronous Colorectal Peritoneal Metastases: A Population- Based Study
}

\author{
C. Bakkersi1, R. J. Lurvink ${ }^{1,2}$ (1) , A. Rijken ${ }^{1}$, S. W. Nienhuijs ${ }^{1}$, N. F. Kok ${ }^{3}$, G. J. Creemers ${ }^{4}$, \\ C. Verhoef ${ }^{5}$, V. E. Lemmens ${ }^{2}$, F. N. van Erning ${ }^{2}$, and I. H. De Hingh ${ }^{1,2,6}$ \\ ${ }^{1}$ Department of Surgery, Catharina Cancer Institute, P. O. Box 1350, Eindhoven, Netherlands; ${ }^{2}$ Department of Research, \\ Netherlands Comprehensive Cancer Organization, Utrecht, Netherlands; ${ }^{3}$ Department of Surgery, Netherlands Cancer \\ Institute, Amsterdam, Netherlands; ${ }^{4}$ Department of Medical Oncology, Catharina Cancer Institute, Eindhoven, \\ Netherlands; ${ }^{5}$ Department of Surgery, Erasmus Medical Center, Rotterdam, Netherlands; ${ }^{6}$ GROW-School for Oncology \\ and Developmental Biology, Maastricht University, Maastricht, Netherlands
}

\begin{abstract}
Background. This study aimed to compare treatment strategies and survival of patients with synchronous colorectal peritoneal metastases (CPM) and patients with metachronous CPM in a nationwide cohort.

Methods. All patients from the Netherlands Cancer Registry with synchronous or metachronous CPM whose primary colorectal cancer (CRC) was diagnosed between 1 January and 30 June 2015 were included in the study. Treatments were categorized as (A) cytoreductive surgery and hyperthermic intraperitoneal chemotherapy [CRSHIPEC]; (B) palliative treatment; or (C) best supportive care. Overall survival (OS) for all the patients and diseasefree survival (DFS) for those who underwent CRS-HIPEC were compared between the two groups.

Results. Of 7233 patients, 743 had a diagnosis of CPM, including 409 patients with synchronous CPM and 334 patients with metachronous CPM. The median OS was 8.1
\end{abstract}

C. Bakkers and R. J. Lurvink are equally contributing first authors.

Supplementary Information The online version contains supplementary material available at https://doi.org/10.1245/s10434021-10190-z.

(C) The Author(s) 2021

First Received: 12 January 2021

Accepted: 1 May 2021;

Published Online: 2 June 2021

I. H. De Hingh

e-mail: Ignace.d.hingh@catharinaziekenhuis.nl months for the patients with synchronous CPM versus 12 months for the patients with metachronous CPM ( $p=$ 0.003). After multivariable correction, OS no longer differed between the patients with synchronous CPM and those with metachronous CPM (HR 1.03 [0.83-1.27]). The patients with metachronous CPM more often underwent CRS-HIPEC than the patients with synchronous CPM (16 $\%$ vs $8 \% ; p=0.001)$. The two groups did not differ statistically in terms of DFS and OS (median DFS, 21.5 vs 14.1 months, respectively; $p=0.094$; median OS, 37.8 vs. 35.8 months, respectively; $p=0.553$ ).

Conclusion. This population-based study showed that survival for the patients with synchronous CPM and patients with metachronous CPM did not significantly differ. This suggests that a similar prognosis may be expected for patients selected for treatment regardless of the onset of CPM.

Colorectal cancer (CRC) is the third most common malignancy worldwide. ${ }^{1}$ Approximately one third of patients are confronted with metastatic disease, either at the time of diagnosis or later during follow-up evaluation after curative treatment. ${ }^{2}$ After the liver, the peritoneum is the second most common metastatic site of CRC. ${ }^{3,4}$ Colorectal peritoneal metastases (CPM), occurring in about $10 \%$ of CRC patients, are diagnosed during the initial treatment of the primary tumor (synchronous peritoneal metastases) or during follow-up evaluation (metachronous peritoneal metastases). ${ }^{2}$ 
Although the risk factors for synchronous and metachronous CPM are alike, ${ }^{2}$ it is unknown whether the tumor behavior differs between synchronous peritoneal metastases and metachronous peritoneal metastases. A different tumor behavior may result in a different prognosis and therefore require adjusted treatment strategies.

Recently, an Italian society of experts in peritoneal surface malignancies defined and approved different diagnostic and therapeutic algorithms for synchronous peritoneal metastases and metachronous peritoneal metastases. ${ }^{7}$ However, most international guidelines do not take the presentation of CPM into account in recommendations regarding treatment. ${ }^{8-11}$ Also, in some randomized trials, the synchronous or metachronous presentation of CPM is used as a stratification factor. ${ }^{12}$ Still, it remains unclear whether any differences exist between synchronous CPM and metachronous CPM and, if so, how this affects prognosis in an unselected population.

This population-based study aimed to provide insight into the treatment strategies and prognosis of patients with synchronous CPM and those with metachronous CPM and to identify characteristics associated with prognosis, providing an up-to-date basis for future clinical research investigating patients with synchronous CPM and those with metachronous CPM.

\section{METHODS}

\section{Data Source}

Data from the Netherlands Cancer Registry (NCR) were used for the performance of the current nationwide population-based cohort study. The NCR registers all newly diagnosed malignancies in the Netherlands, and trained data managers from the NCR routinely collect patient, tumor, and treatment characteristics. Each year, the vital status of all patients is checked by linkage to the municipal administrative database, in which all deaths of Dutch inhabitants are registered.

For the current study, the latest linkage to the municipal administrative database was performed in February 2020. In 2019, all patients with a diagnosis of CRC determined between 1 January and 30 June 2015 were reassessed to obtain follow-up information on locoregional and/or systemic recurrences and their treatment. All data were rendered anonymous, obviating approval for the study by the medical ethics committee.

\section{Patients and Characteristics}

The study excluded patients with an appendiceal tumor, a neuro-endocrine tumor, or a tumor with histology other than adenocarcinoma. For the analyses, the study included only patients who experienced synchronous or metachronous peritoneal metastases, defined as present in any of the following metastatic locations according to the International Classification of Disease-Oncology [ICD-O]: C16.0-C16.9, C17.0-C17.9, C18.0-C18.9, C19.9, C20.9, C21.8, C23.9, C26.9, C48.0-C48.8, C49.4-C49.5, C52.9, C53.9, C54.0-C54.9, C55.9, C56.9, C57.0-C57.8, C66.9, C67.0-C67.9, or C76.2). All metastases in other locations were registered as systemic metastases. Metastases were considered synchronous if diagnosed 90 days or less after surgery for primary CRC or 90 days or less after diagnosis if no surgery for primary CRC was performed. Among the patients without synchronous peritoneal metastases, only those who underwent surgery for primary CRC were evaluated for the development of metachronous metastases. Metastases were considered metachronous if diagnosed longer than 90 days after surgery for primary CRC.

The primary tumor location was subcategorized according to the ICD-O as (1) right-sided colon (C18.0, C18.2-18.4): cecum, ascending colon, hepatic flexure, transverse colon; (2) left-sided colon (C18.5-18.7): splenic flexure, descending colon and sigmoid; or (3) rectum (C19.9-20.9): rectosigmoid and rectum. The primary tumor histology was defined as adenocarcinoma (8000, $8010,8020,8140,8144,8210,8211,82208255,8261$, $8262,8263,8560$ ), mucinous adenocarcinoma (8480, 8481), or signet ring cell carcinoma (8490).

The treatment of peritoneal metastases was defined as (1) cytoreductive surgery and hyperthermic intraperitoneal chemotherapy [CRS-HIPEC] with or without systemic chemotherapy and/or radiotherapy; (2) palliative treatment: systemic chemotherapy, metastasectomy, and/or radiotherapy without curative intent; or (3) no tumor-directed treatment, only best supportive care (BSC).

\section{Statistical Analyses}

The baseline characteristics of the patients with synchronous peritoneal metastases were compared with those of patients with metachronous peritoneal metastases. Continuous variables are presented as mean \pm standard deviation and were compared using the unpaired $t$ test. Categorical variables are presented as number (\%) and were compared with the chi-square test. Different treatment strategies between the patients with synchronous and those with metachronous peritoneal metastases were compared using the chi-square test. All the tests were two-sided, and a $p$ value lower than 0.05 was considered statistically significant.

Median overall survival (OS) was determined with the Kaplan-Meier method and compared between the patients with synchronous CPM and those with metachronous CPM 
as well as between the patients treated with different treatment strategies using the log-rank test. The median OS was calculated from the first diagnosis of peritoneal metastases until death or loss to follow-up evaluation. Disease free survival (DFS) was determined only for the patients who underwent CRS-HIPEC and was calculated from the date of CRS-HIPEC until the diagnosis of metastases (locoregional and/or systemic metastases) thereafter.

Univariable Cox regression analyses were performed for the patients with peritoneal metastases (as one group) and for the patients with synchronous or metachronous peritoneal metastases (as two groups) to identify risk factors affecting OS. To prevent overfitting, variables with a $p$ value lower than 0.10 were subsequently combined in multivariable Cox regression models with respect to the number of deaths in each group (10 deaths per degree of freedom). Dummy variables of missing data were included in the multivariable analyses. All analyses were performed using SAS statistical software (SAS system 9.4, SAS Institute, Cary, NC, USA).

\section{RESULTS}

\section{Study Population}

Between 1 January and 30 June 2015, CRC was diagnosed for 7233 patients. Of these patients, 409 (5.7\%) presented with synchronous peritoneal metastases. During follow-up evaluation, metachronous peritoneal metastases was diagnosed for $334(5.7 \%)$ of 5860 patients without synchronous peritoneal metastases who underwent surgery for primary CRC. The median follow-up period after surgery was 38.4 months (interquartile range [IQR], 15.3-45.4 months). The baseline characteristics of the patients with synchronous CPM and those with metachronous CPM are presented in Table 1. Poorly differentiated or undifferentiated tumor, T4 tumor stage, and synchronous systemic metastases were more frequently diagnosed for the patients with synchronous peritoneal metastases than for those with metachronous peritoneal metastases.

\section{Treatments}

Figure 1 provides an overview of the treatment strategies applied for the patients with synchronous or metachronous peritoneal metastases. Overall, the distribution of applied treatment strategies differed significantly between patients with synchronous peritoneal metastases and those with metachronous peritoneal metastases $(p<$ $0.001)$. The patients with metachronous peritoneal metastases more frequently underwent CRS-HIPEC (16\% vs 8
$\% ; p=0.001)$ and less frequently underwent palliative treatment $(55 \%$ vs $69 \% ; p<0.001)$ than the patients with synchronous peritoneal metastases. The number of patients who received BSC was similar between the metachronous peritoneal metastases group and synchronous peritoneal metastases group ( $29 \%$ vs $23 \%$; $p=0.051$ ).

\section{Disease-Free Survival}

The DFS of the patients with synchronous or metachronous peritoneal metastases who underwent CRSHIPEC is shown in Fig. 2. The median DFS was 14.1 months (IQR, 8.2-29.2 months) for the patients with synchronous peritoneal metastases and 21.5 months (IQR, 8.0, not reached) for the patients with metachronous peritoneal metastases, but the difference was not significant $(p=$ 0.094). The site or sites of first recurrence after CRSHIPEC in the patients with synchronous or metachronous peritoneal metastases are shown in Fig. 3. No differences in the pattern of recurrence were observed between the patients with synchronous peritoneal metastases and those with metachronous peritoneal metastases $(p=0.950)$.

\section{Overall Survival}

The median OS of all the patients with peritoneal metastases was 9.1 months (IQR, 2.6-22.5 months), with a 1 -year OS of $44 \%$ and a 3 -year OS of $13 \%$. The patients with synchronous peritoneal metastases had a worse OS (median, 8.1 months; IQR, 2.0-20.5 months) than the patients with metachronous peritoneal metastases (12.0 months; IQR, 3.5-25.5 months) ( $p=0.003$; Fig. 4a). However, after multivariable Cox regression analysis, the presentation of peritoneal metastases did not affect OS significantly (metachronous peritoneal metastases vs synchronous peritoneal metastases: HR, 1.03; $95 \%$ CI 0.83-1.27) (Table 2).

For the patients who underwent CRS-HIPEC, the median OS of the entire cohort was 36 months (IQR, 22.5 months, not reached). The median OS did not differ significantly between the patients with synchronous peritoneal metastases (35.8 months; IQR, 26.2 months, not reached) and those with metachronous peritoneal metastases $(37.8$ months; IQR, 17.3 months, not reached) ( $p=0.553$; Fig. 4b).

For the patients who received palliative treatment, the median OS of the entire cohort was 12.2 months (IQR, 4.9-22.7 months). The OS was worse for the patients with synchronous peritoneal metastases (median, 10.0 months; IQR 3.6-20.6 months) than for those with metachronous peritoneal metastases (15.4 months; IQR, 6.8-25.6 months; $p<0.001$ (Fig. 4c). 
TABLE 1 Baseline characteristics

\begin{tabular}{|c|c|c|c|}
\hline & Synchronous PM $(n=409) n(\%)$ & Metachronous PM $(n=334) n(\%)$ & $p$ value \\
\hline Mean age (years) & $69 \pm 12$ & $67 \pm 11$ & 0.062 \\
\hline \multicolumn{4}{|l|}{ Sex } \\
\hline Male & $225(55)$ & $185(55)$ & \multirow[t]{2}{*}{0.918} \\
\hline Female & $184(45)$ & $149(45)$ & \\
\hline \multicolumn{4}{|l|}{ ASA } \\
\hline ASA 1 & $29(7)$ & $63(19)$ & \multirow[t]{4}{*}{$<0.001$} \\
\hline ASA 2 & $138(34)$ & $165(49)$ & \\
\hline $\mathrm{ASA} \geq 3$ & $75(18)$ & $57(17)$ & \\
\hline Missing data ${ }^{\mathrm{a}}$ & $167(41)$ & $49(15)$ & \\
\hline \multicolumn{4}{|l|}{ Primary tumor location } \\
\hline Right-sided colon & $186(45)$ & $126(38)$ & \multirow[t]{3}{*}{$<0.001$} \\
\hline Left-sided colon & $173(42)$ & $132(39)$ & \\
\hline Rectum & $50(12)$ & $76(23)$ & \\
\hline \multicolumn{4}{|l|}{ Tumor differentiation } \\
\hline Good/moderate & $167(41)$ & $248(74)$ & \multirow[t]{3}{*}{0.002} \\
\hline Poor/undifferentiated & $67(16)$ & $52(16)$ & \\
\hline Missing data ${ }^{\mathrm{a}}$ & $175(43)$ & $34(10)$ & \\
\hline \multicolumn{4}{|l|}{ Tumor histology } \\
\hline Adenocarcinoma & $313(77)$ & $282(86)$ & \multirow[t]{3}{*}{0.001} \\
\hline Mucinous adenocarcinoma & $65(16)$ & $35(11)$ & \\
\hline Signet ring cell carcinoma & $31(6)$ & $9(3)$ & \\
\hline \multicolumn{4}{|l|}{ Tumor stage } \\
\hline T0-3 & $118(29)$ & $210(63)$ & \multirow[t]{3}{*}{$<0.001$} \\
\hline $\mathrm{T} 4$ & $192(47)$ & $124(37)$ & \\
\hline Missing data ${ }^{a}$ & $99(24)$ & $0(0)$ & \\
\hline \multicolumn{4}{|l|}{ Nodal stage } \\
\hline No & $83(20)$ & $97(29)$ & \multirow[t]{4}{*}{$<0.001$} \\
\hline N1 & $104(25)$ & $126(38)$ & \\
\hline $\mathrm{N} 2$ & $165(40)$ & $109(32)$ & \\
\hline Missing data ${ }^{a}$ & $57(14)$ & $2(1)$ & \\
\hline \multicolumn{4}{|c|}{ Synchronous systemic metastases } \\
\hline No & $166(41)$ & $252(75)$ & \multirow[t]{2}{*}{$<0.001$} \\
\hline Yes & $243(59)$ & $82(25)$ & \\
\hline \multicolumn{4}{|l|}{ Colon perforation } \\
\hline No & $203(50)$ & $293(88)$ & \multirow[t]{3}{*}{0.106} \\
\hline Yes & $24(6)$ & $21(6)$ & \\
\hline Missing data ${ }^{a}$ & $182(44)$ & $20(6)$ & \\
\hline
\end{tabular}

PM, peritoneal metastases; ASA, American Society of Anesthesiologists

${ }^{\mathrm{a}}$ Missing data were not included in the chi-square analyses.

For the patients who received only BSC, the median OS of the entire cohort was 1.8 months (IQR, 0.9-3.9 months). The OS was worse for the patients with synchronous peritoneal metastases (1.3 months; IQR, 0.6-3.2 months) than for the patients with metachronous peritoneal metastases (2.1 months; IQR, 1.0-4.6 months; $p=0.021$ (Fig. 4d).

\section{Factors Associated With Overall Survival}

The results of the univariable Cox regression analyses for the OS of the patients with synchronous and those with metachronous peritoneal metastases are shown in Table S1. The results of the multivariable Cox regression analyses of 
FIG. 1. Treatment strategies for patients with synchronous or metachronous colorectal peritoneal metastases.

FIG. 2. Disease-free survival of patients with synchronous or metachronous colorectal peritoneal metastases after cytoreductive surgery and hyperthermic intraperitoneal chemotherapy (CRS-HIPEC).

FIG. 3. Sites of first recurrent disease after cytoreductive surgery and hyperthermic intraperitoneal chemotherapy (CRS-HIPEC) in patients with synchronous or metachronous colorectal peritoneal metastases.
Synchronous PM

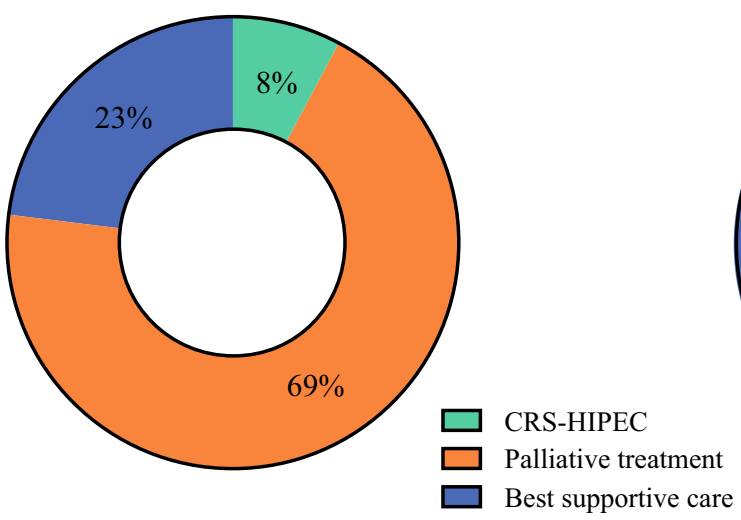

Metachronous PM

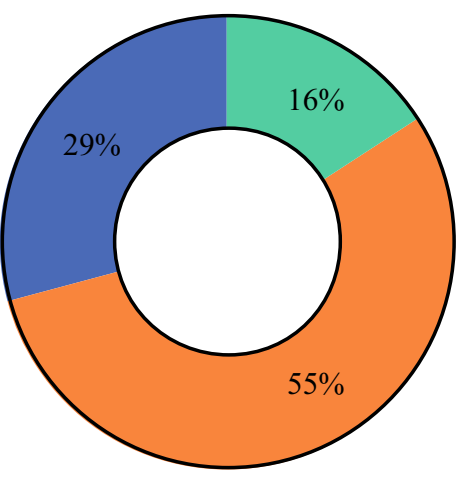

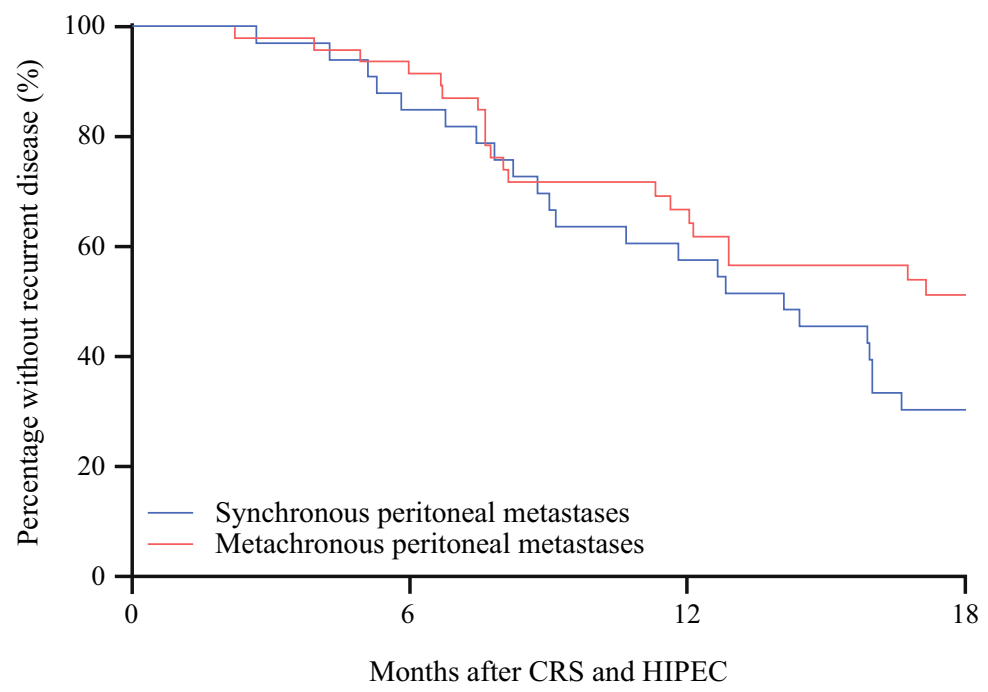

Number at risk

Synchronous PM

Metachronous PM

Number censored

Synchronous PM

Metachronous PM
1

8

\section{Synchronous PM}

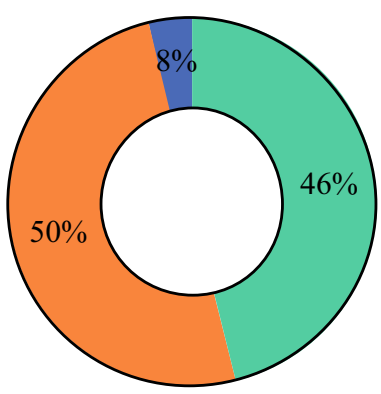

Peritoneal recurrence

Systemic recurrence

Peritoneal and systemic recurrence

\section{Metachronous PM}

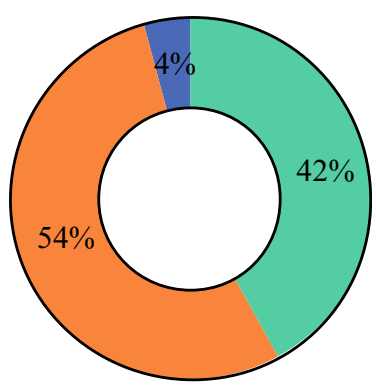


A All patients within the study

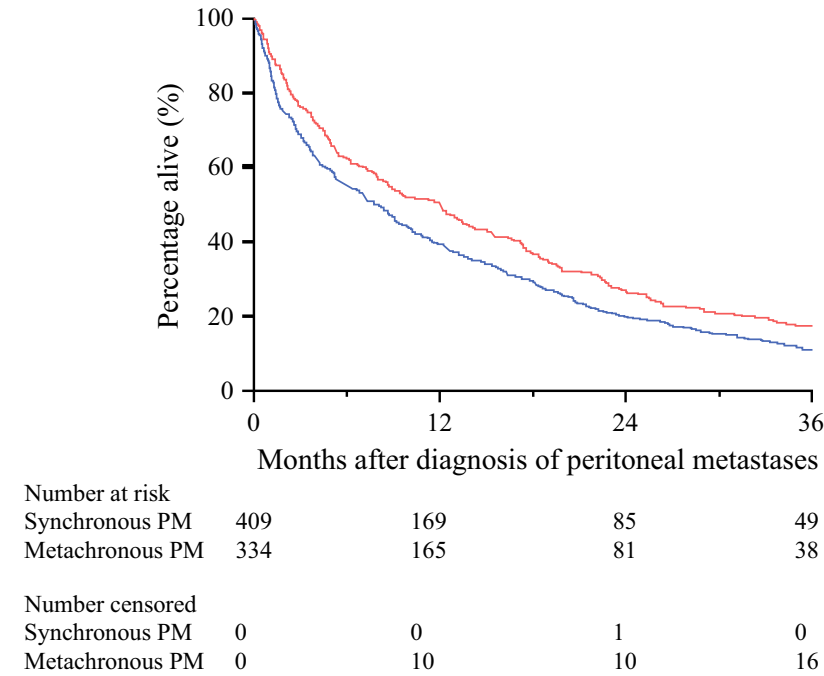

C Patients who underwent palliative treatment

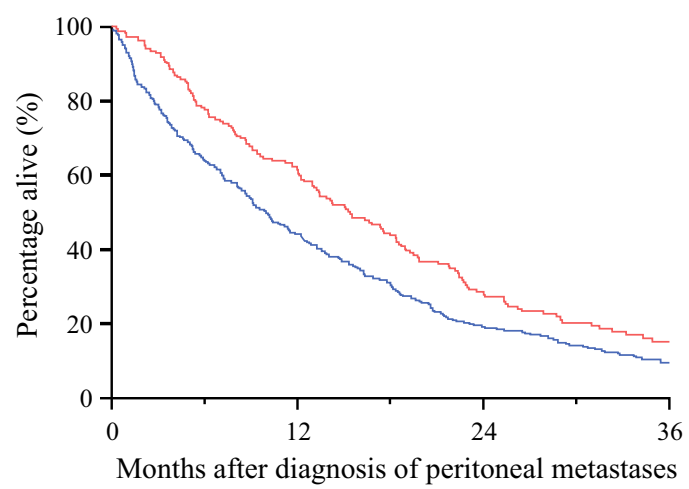

Number at risk

Synchronous PM

283
184

\section{2}

114

57
47

Number censored

Synchronous PM

Metachronous PM

$$
\begin{aligned}
& 0 \\
& 0
\end{aligned}
$$

B Patients who underwent CRS-HIPEC

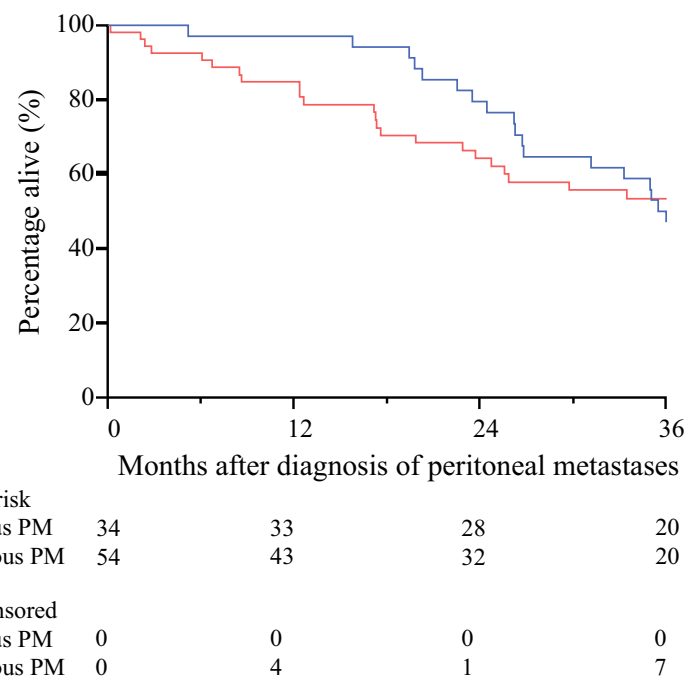

D Patients who received best supportive care

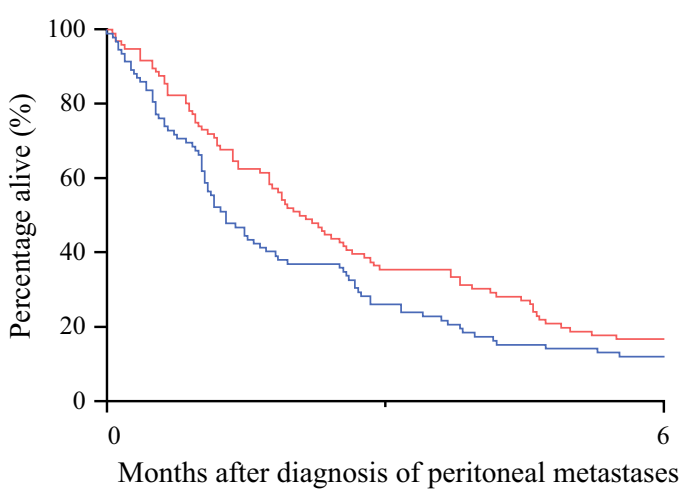

Number at risk

Synchronous PM 92

Metachronous PM 96

13

Number censored

Synchronous PM 0

Metachronous PM 0
Number at risk

Metachronous PM

Number censore

Synchronous PM 
TABLE 2 Uni- and multivariable Cox regression analyses for overall survival of the entire study cohort

\begin{tabular}{|c|c|c|c|c|c|c|c|}
\hline & \multirow[t]{2}{*}{ Median OS (months) } & \multicolumn{3}{|c|}{ Univariable analyses } & \multicolumn{3}{|c|}{ Multivariable analyses } \\
\hline & & HR & $95 \% \mathrm{CI}$ & $p$ value & HR & $95 \% \mathrm{CI}$ & $p$ value \\
\hline Age (years) & & & & $<0.001$ & & & \\
\hline$<50$ & 15.6 & 0.80 & $0.59-1.09$ & & 0.84 & $0.61-1.15$ & 0.283 \\
\hline $50-74$ & 11.9 & Ref & Ref & & Ref & Ref & Ref \\
\hline$\geq 75$ & 4.2 & 1.74 & $1.47-2.07$ & & 1.05 & $0.86-1.26$ & 0.654 \\
\hline Sex & & & & 0.156 & & & \\
\hline Male & 9.4 & Ref & Ref & & - & - & - \\
\hline Female & 8.7 & 1.12 & $0.96-1.31$ & & - & - & - \\
\hline ASA score & & & & $<0.001$ & & & \\
\hline ASA 1 & 17.6 & 0.72 & $0.55-0.94$ & & 0.92 & $0.69-1.22$ & 0.571 \\
\hline ASA 2 & 12.1 & Ref & Ref & & Ref & Ref & Ref \\
\hline ASA 3-6 & 5.7 & 1.44 & $1.16-1.79$ & & 1.16 & $0.93-1.45$ & 0.202 \\
\hline Missing data & 4.6 & 1.80 & $1.50-2.17$ & & 1.26 & $1.02-1.56$ & 0.034 \\
\hline Primary tumor location & & & & 0.019 & & & \\
\hline Right colon & 7.3 & Ref & Ref & & Ref & Ref & Ref \\
\hline Left colon & 11.4 & 0.79 & $0.66-0.93$ & & 0.87 & $0.73-1.05$ & 0.141 \\
\hline Rectum & 9.7 & 0.87 & $0.69-1.08$ & & 1.12 & $0.88-1.44$ & 0.356 \\
\hline Primary tumor differentiation & & & & $<0.001$ & & & \\
\hline Good/moderate & 14.2 & Ref & Ref & & Ref & Ref & Ref \\
\hline Poor/undifferentiated & 3.6 & 2.52 & $2.03-3.13$ & & 2.00 & $1.57-2.52$ & $<0.001$ \\
\hline Missing data & 5.3 & 1.66 & $1.39-1.98$ & & 1.21 & $0.97-1.51$ & 0.096 \\
\hline Tumor histology & & & & 0.003 & & & \\
\hline Adenocarcinoma & 9.5 & Ref & Ref & & Ref & Ref & Ref \\
\hline Mucinous adenocarcinoma & 9.1 & 0.97 & $0.77-1.22$ & & 0.83 & $0.64-1.07$ & 0.148 \\
\hline Signet ring cell carcinoma & 3.8 & 1.83 & $1.32-2.53$ & & 1.51 & $1.06-2.15$ & 0.024 \\
\hline Tumor stage & & & & $<0.001$ & & & \\
\hline T0-3 & 9.5 & Ref & Ref & & Ref & Ref & Ref \\
\hline $\mathrm{T} 4$ & 11.7 & 1.02 & $0.86-1.21$ & & 1.12 & $0.92-1.35$ & 0.257 \\
\hline Missing data & 3.7 & 2.21 & $1.75-2.79$ & & 1.20 & $0.90-1.60$ & 0.220 \\
\hline Nodal stage & & & & $<0.001$ & & & \\
\hline No & 12.8 & 0.74 & $0.60-0.91$ & & 0.82 & $0.66-1.03$ & 0.087 \\
\hline N1 & 10.8 & 0.91 & $0.75-1.10$ & & 1.01 & $0.83-1.23$ & 0.937 \\
\hline $\mathrm{N} 2$ & 8.3 & Ref & Ref & & Ref & Ref & Ref \\
\hline Missing data & 2.8 & 2.28 & $1.71-3.04$ & & 1.74 & $1.27-2.38$ & $<0.001$ \\
\hline Synchronous systemic metastases & & & & $<0.001$ & & & \\
\hline No & 12.1 & Ref & Ref & & Ref & Ref & Ref \\
\hline Yes & 6.7 & 1.36 & $1.17-1.59$ & & 1.22 & $1.02-1.47$ & 0.034 \\
\hline Tumor perforation & & & & $<0.001$ & & & \\
\hline No & 12.2 & Ref & Ref & & Ref & Ref & Ref \\
\hline Yes & 9.4 & 0.98 & $0.70-1.38$ & & 0.99 & $0.69-1.41$ & 0.958 \\
\hline Missing data & 8.2 & 1.85 & $1.55-2.19$ & & 1.06 & $0.86-1.31$ & 0.593 \\
\hline Presentation of PM & & & & 0.003 & & & \\
\hline Synchronous & 8.1 & Ref & Ref & & Ref & Ref & Ref \\
\hline Metachronous & 12.0 & 0.79 & $0.67-0.92$ & & 1.03 & $0.83-1.27$ & 0.813 \\
\hline Treatment of PM & & & & $<0.001$ & & & \\
\hline Best supportive care & 1.8 & 4.56 & $3.77-5.51$ & & 4.44 & $3.57-5.52$ & $<0.001$ \\
\hline Palliative treatment & 12.2 & Ref & Ref & & Ref & Ref & Ref \\
\hline CRS-HIPEC & 36.0 & 0.31 & $0.23-0.43$ & & 0.40 & $0.29-0.55$ & $<0.001$ \\
\hline
\end{tabular}

OS, overall survival; HR, hazard ratio; CI, confidence interval; ASA, American Society of Anesthesiologists; PM, peritoneal metastases; CRS, cytoreductive surgery; HIPEC, hyperthermic intraperitoneal chemotherapy 
TABLE 3 Multivariable Cox regression analyses for overall survival of patients with synchronous and metachronous peritoneal metastases

\begin{tabular}{|c|c|c|c|c|c|c|c|c|}
\hline & \multicolumn{4}{|c|}{ Synchronous PM } & \multicolumn{4}{|c|}{ Metachronous PM } \\
\hline & $\begin{array}{l}\text { Median OS } \\
\text { (months) }\end{array}$ & HR & $95 \% \mathrm{CI}$ & $p$ value & $\begin{array}{l}\text { Median OS } \\
\text { (months) }\end{array}$ & HR & $95 \% \mathrm{CI}$ & $p$ value \\
\hline \multicolumn{9}{|l|}{ Age (years) } \\
\hline$<50$ & 15.9 & 0.86 & $0.56-1.32$ & 0.494 & 14.5 & 0.84 & $0.52-1.35$ & 0.472 \\
\hline $50-74$ & 10.0 & Ref & Ref & Ref & 14.3 & Ref & Ref & Ref \\
\hline$\geq 75$ & 3.8 & 0.95 & $0.75-1.21$ & 0.672 & 4.6 & 1.19 & $0.86-1.64$ & 0.294 \\
\hline \multicolumn{9}{|l|}{ Sex } \\
\hline Male & 8.4 & - & - & - & 12.2 & Ref & Ref & Ref \\
\hline Female & 7.3 & - & - & - & 10.4 & 1.01 & $0.78-1.30$ & 0.969 \\
\hline \multicolumn{9}{|l|}{ ASA stage } \\
\hline ASA 1 & 18.6 & 0.88 & $0.55-1.38$ & 0.567 & 16.4 & 0.95 & $0.65-1.38$ & 0.775 \\
\hline ASA 2 & 11.3 & Ref & Ref & Ref & 12.2 & Ref & Ref & Ref \\
\hline $\mathrm{ASA} \geq 3$ & 5.2 & 1.43 & $1.05-1.94$ & 0.023 & 6.1 & 0.87 & $0.62-1.23$ & 0.420 \\
\hline Missing data & 3.8 & 1.31 & $1.01-1.72$ & 0.049 & 10.4 & 1.15 & $0.80-1.67$ & 0.457 \\
\hline \multicolumn{9}{|l|}{ Primary tumor location } \\
\hline Right-sided colon & 7.0 & Ref & Ref & Ref & 8.5 & - & - & - \\
\hline Left-sided colon & 9.9 & 0.93 & $0.74-1.17$ & 0.545 & 13.5 & - & - & - \\
\hline Rectum & 6.3 & 1.63 & $1.15-2.31$ & 0.006 & 12.4 & - & - & - \\
\hline \multicolumn{9}{|l|}{ Primary tumor differentiation } \\
\hline Good/moderate & 14.9 & Ref & Ref & Ref & 14.1 & Ref & Ref & Ref \\
\hline Poor/none & 3.7 & 2.06 & $1.48-2.85$ & $<\mathbf{0 . 0 0 1}$ & 3.2 & 2.00 & $1.42-2.80$ & $<\mathbf{0 . 0 0 1}$ \\
\hline Missing data & 5.3 & 1.23 & $0.94-1.59$ & 0.130 & 12.1 & 0.75 & $0.43-1.30$ & 0.301 \\
\hline \multicolumn{9}{|l|}{ Tumor histology } \\
\hline Adenocarcinoma & 8.2 & Ref & Ref & Ref & 13.0 & Ref & Ref & Ref \\
\hline Mucinous adenocarcinoma & 9.9 & 0.81 & $0.59-1.11$ & 0.191 & 6.6 & 1.22 & $0.74-2.01$ & 0.434 \\
\hline Signet ring cell carcinoma & 4.2 & 1.32 & $0.87-2.01$ & 0.192 & 3.2 & 2.70 & $1.24-5.88$ & 0.012 \\
\hline \multicolumn{9}{|l|}{ Tumor stage } \\
\hline $\mathrm{T} 0-3$ & 7.8 & Ref & Ref & Ref & 12.4 & - & - & - \\
\hline $\mathrm{T} 4$ & 12.0 & 1.19 & $0.91-1.56$ & 0.203 & 11.2 & - & - & - \\
\hline Missing data & 3.7 & 1.25 & $0.91-1.71$ & 0.163 & & - & - & - \\
\hline \multicolumn{9}{|l|}{ Nodal stage } \\
\hline No & 8.4 & 0.96 & $0.71-1.31$ & 0.802 & 17.9 & 0.64 & $0.45-0.92$ & 0.015 \\
\hline N1 & 9.0 & 0.97 & $0.73-1.28$ & 0.812 & 12.2 & 1.08 & $0.80-1.46$ & 0.622 \\
\hline $\mathrm{N} 2$ & 10.9 & Ref & Ref & Ref & 5.3 & Ref & Ref & Ref \\
\hline Missing data & 2.8 & 1.70 & $1.21-2.39$ & 0.002 & 10.5 & 2.06 & $0.49-8.64$ & 0.323 \\
\hline \multicolumn{9}{|c|}{ Synchronous systemic metastases } \\
\hline No & 10.6 & Ref & Ref & Ref & 12.7 & - & - & - \\
\hline Yes & 5.5 & 1.18 & $0.93-1.49$ & 0.174 & 8.7 & - & - & - \\
\hline \multicolumn{9}{|l|}{ Tumor perforation } \\
\hline No & 12.6 & Ref & Ref & Ref & 12.0 & - & - & - \\
\hline Yes & 13.3 & 0.80 & $0.49-1.30$ & 0.366 & 7.6 & - & - & - \\
\hline Missing data & 7.0 & 1.24 & $0.96-1.59$ & 0.100 & 13.1 & - & - & - \\
\hline \multicolumn{9}{|c|}{$\begin{array}{l}\text { Adjuvant treatment after primary surgery for colorectal } \\
\text { cancer }\end{array}$} \\
\hline No & NA & NA & NA & NA & 9.0 & Ref & Ref & Ref \\
\hline Yes & NA & NA & NA & NA & 17.4 & 0.84 & $0.63-1.13$ & 0.250 \\
\hline \multicolumn{9}{|l|}{ Treatment of PM } \\
\hline Best supportive care & 1.3 & 4.11 & $3.00-5.63$ & $<0.001$ & 2.1 & 4.95 & $3.60-6.81$ & $<\mathbf{0 . 0 0 1}$ \\
\hline Palliative treatment & 10.0 & Ref & Ref & Ref & 15.4 & Ref & Ref & Ref \\
\hline CRS- HIPEC & 35.8 & 0.35 & $0.22-0.57$ & $<\mathbf{0 . 0 0 1}$ & 37.8 & 0.43 & $0.28-0.67$ & $<\mathbf{0 . 0 0 1}$ \\
\hline
\end{tabular}

OS, overall survival; HR, adjusted hazard ratio; CI, confidence interval; ASA, American Society of Anesthesiologists; NA, not applicable; PM, peritoneal metastases; CRS, cytoreductive surgery; HIPEC, hyperthermic intraperitoneal chemotherapy 
carcinoma (HR 2.70; $95 \%$ CI 1.24-5.88). An N0 status was significantly associated with a better OS (HR 0.64; 95 $\%$ CI 0.45-0.92). Treatment with CRS-HIPEC was significantly associated with a better OS than palliative treatment (HR 0.43; 95 \% CI 0.28-0.67). Best supportive care was significantly associated with a worse OS than palliative treatment (HR 4.95; $95 \%$ CI 3.60-6.81).

\section{DISCUSSION}

To the best of our knowledge, the current study was the first to compare treatment strategies and survival between patients with synchronous CPM and those with metachronous CPM in a nationwide cohort. Overall survival did not differ significantly between the patients with synchronous peritoneal metastases and those with metachronous peritoneal metastases after correction for covariables, although the patients with metachronous peritoneal metastases were more often treated with CRS-HIPEC than the patients with synchronous peritoneal metastases. Moreover, neither OS nor DFS differed significantly the between patients with synchronous peritoneal metastases and those with metachronous peritoneal metastases who underwent CRSHIPEC.

Although the OS for the patients with synchronous peritoneal metastases and those with metachronous peritoneal metastases did not differ significantly after correction for covariables, the more favorable crude OS of the patients with metachronous peritoneal metastases could be explained in different ways. First, the late presentation of metachronous peritoneal metastases may itself suggest a less aggressive tumor behavior, thus resulting in better OS. However, metachronous peritoneal metastases occur primarily in patients with high-risk tumors, who are designated for adjuvant systemic therapy after primary surgery according to most national and international guidelines to minimize the risk of metastatic recurrence. $^{10,13}$ Therefore, if metachronous peritoneal metastases occur regardless of adjuvant systemic therapy, it may instead suggest a more aggressive tumor biology.

Second, the better crude OS for patients with metachronous peritoneal metastases may have been related to lead-time bias. After primary treatment for CRC, these patients underwent standardized follow-up evaluation for several years, which may have resulted in the early diagnosis of less advanced metachronous peritoneal metastases. On the other hand, the patients with synchronous peritoneal metastases may have remained unnoticed until an advanced stage of disease given the absence of clinical symptoms in most of these patients. ${ }^{14}$ The higher number of patients with metachronous peritoneal metastases treated with CRS-HIPEC compared with the number of patients who had synchronous peritoneal metastases treated with CRSHIPEC in the current study supports this hypothesis. Furthermore, synchronous CPMs are frequently discovered (in an emergency setting) in non-academic hospitals that are not specialized HIPEC centers, which is known to affect the likelihood of a patient eventually undergoing CRSHIPEC. $^{15}$

In the current study, DFS and OS for the patients with synchronous peritoneal metastases and those with metachronous peritoneal metastases who underwent CRSHIPEC were nonsignificantly different. Another comparative study, which included patients from two Dutch HIPEC centers, showed a significantly longer DFS (15 months) for 231 patients with synchronous peritoneal metastases compared with 11 months for 202 patients who had metachronous peritoneal metastases, without a difference in OS. ${ }^{16}$ Recently, Min Wong et al. ${ }^{5}$ demonstrated no differences in DFS, but showed a better OS for patients with metachronous peritoneal metastases (45 months) than for patients with synchronous peritoneal metastases (27 months). A similar trend was observed in a third study, with no difference in DFS but a better OS for patients with metachronous peritoneal metastases (28 months) than for patients with synchronous peritoneal metastases (7 months). However, in the latter study, survival was calculated from the diagnosis of primary CRC instead of from the diagnosis of peritoneal metastases, explaining the much longer survival of patients with metachronous CPM. ${ }^{6}$

Other population-based studies that reported the survival of all patients with synchronous peritoneal metastases demonstrated a median OS of 8 to 9 months (diagnosis in 2002-2011), ${ }^{4,17}$ similar to that of the current study. For metachronous peritoneal metastases, a median OS of 6 months was reported (diagnosis of primary CRC in 2003-2008), ${ }^{18}$ which is lower than the OS for the patients in the current study. This improvement over time for patients with metachronous peritoneal metastases may be due to improved diagnostic methods and better follow-up evaluation, with higher awareness for metachronous peritoneal metastases after primary surgery for CRC, especially because no improvement was found in patients with synchronous peritoneal metastases. However, currently available data on the association between the intensity of follow-up evaluation after primary CRC treatment and OS is rather contradictory to two meta-analyses conducted in $2019^{19}$ and $2016^{20}$ concluding that the intensified surveillance of CRC patients does not result in a cancer-specific survival benefit. Furthermore, a systematic review from 2017 concluded that although patients with stages 1 to 3 CRC may experience a survival benefit, the existence of this benefit is questionable for patients with stage $4 \mathrm{CRC}$. $^{21}$ In addition, a randomized controlled trial concluded that intensified carcinoembryonic antigen (CEA) measurements 
resulted in earlier recurrence detection and a higher proportion of patients who could be treated with curative intent. However, this did not result in a survival benefit. ${ }^{22,23}$ As previously noted, patients with synchronous CPM were less likely to be treated with CRS-HIPEC, which may be responsible for this phenomenon.

The extent of peritoneal metastases (peritoneal cancer index [PCI]) was unknown for the patients included in the current study because this is not registered by the NCR. The PCI is known to affect prognosis ${ }^{24}$ and, hypothetically, the patients with metachronous peritoneal metastases may have had a lower PCI than the patients with synchronous peritoneal metastases, explaining the higher percentage of patients who had metachronous CPM treated with CRSHIPEC. However, such a difference was not observed in previous studies. ${ }^{5,16}$ Furthermore, the primary tumor being in situ in patients with synchronous peritoneal metastases may have had a negative impact on treatment and prognosis. Moreover, some patients with metachronous peritoneal metastases were excluded from this analysis if they had not undergone surgery for primary CRC. These patients may have had a worse prognosis because they were not able to undergo surgery. The exclusion of patients who did not undergo surgery may have led to an overestimation of the OS in the group of patients with metachronous peritoneal metastases. Also, selection bias likely will have influenced the received treatment, possibly resulting in overestimation of the beneficial effect of CRSHIPEC and, to a lesser extent, palliative treatment because patients who are fit enough to receive treatment are more likely to actually undergo treatment than patients with a poor clinical condition. Unfortunately, the NCR does not register the reason for the choosing or not choosing of a certain treatment. Still, all patients were treated according to the national guideline for $\mathrm{CRC}$, which defines the selection criteria for eligibility to receive CRS-HIPEC (e.g., PCI $<20$, limited small bowel involvement, absence of systemic metastases).

In conclusion, the OS did not differ significantly between the synchronous CPM and metachronous CPM patients. Also, within the subgroup of patients treated with CRS-HIPEC, DFS and OS as well as the pattern of recurrence were comparable. This suggests that a similar prognosis may be expected for patients selected to undergo treatment regardless of the onset of CPM.

DISCLOSURE I. H. De Hingh reports an unrestricted research grant from RanD/QPS and Roche paid to the institute outside the submitted work. The remaining authors have no conflicts of interest.

OPEN ACCESS This article is licensed under a Creative Commons Attribution 4.0 International License, which permits use, sharing, adaptation, distribution and reproduction in any medium or format, as long as you give appropriate credit to the original author(s) and the source, provide a link to the Creative Commons licence, and indicate if changes were made. The images or other third party material in this article are included in the article's Creative Commons licence, unless indicated otherwise in a credit line to the material. If material is not included in the article's Creative Commons licence and your intended use is not permitted by statutory regulation or exceeds the permitted use, you will need to obtain permission directly from the copyright holder. To view a copy of this licence, visit http://creativecommons. org/licenses/by/4.0/.

\section{REFERENCES}

1. World Health Organisation Global Cancer Observatory. https://gc o.iarc.fr/today/home. Accessed 1 Jan 2021.

2. Lurvink RJ, Bakkers C, Rijken A, et al. Increase in the incidence of synchronous and metachronous peritoneal metastases in patients with colorectal cancer: a nationwide study. Eur J Surg Oncol. 2020. https://doi.org/10.1016/j.ejso.2020.11.135.

3. van Gestel YRBM, de Hingh IHJT, van Herk-Sukel MPP, et al. Patterns of metachronous metastases after curative treatment of colorectal cancer. Cancer Epidemiol. 2014. https://doi.org/10.10 16/j.canep.2014.04.004.

4. van der Geest LGM, Lam-Boer J, Koopman M, Verhoef C, Elferink MAG, de Wilt JHW. Nationwide trends in incidence, treatment and survival of colorectal cancer patients with synchronous metastases. Clin Exp Metastasis. 2015. https://doi.org/ 10.1007/s10585-015-9719-0.

5. Wong JSM, Tan GHC, Chia CS, Ong J, Ng WY, Teo MCC. The importance of synchronicity in the management of colorectal peritoneal metastases with cytoreductive surgery and hyperthermic intraperitoneal chemotherapy. World J Surg Oncol. 2020. h ttps://doi.org/10.1186/s12957-020-1784-4.

6. Jayne DG, Fook S, Loi C, Seow-Choen F. Peritoneal carcinomatosis from colorectal cancer. Br J Surg. 2002. https://doi.org/ 10.1046/j.1365-2168.2002.02274.x.

7. Sommariva A, Ansaloni L, Baiocchi GL, et al. Diagnostic and therapeutic algorithm for colorectal peritoneal metastases: a consensus of the peritoneal surface malignancies onco-team of the Italian society of surgical oncology. Eur J Surg Oncol. 2020. https://doi.org/10.1016/j.ejso.2020.09.035.

8. Bushati M, Rovers KP, Sommariva A, et al. The current practice of cytoreductive surgery and HIPEC for colorectal peritoneal metastases: results of a worldwide web-based survey of the Peritoneal Surface Oncology Group International (PSOGI). Eur J Surg Oncol. 2018. https://doi.org/10.1016/j.ejso.2018.07.003.

9. Klaver CEL, Groenen H, Morton DG, Laurberg S, Bemelman WA, Tanis PJ. Recommendations and consensus on the treatment of peritoneal metastases of colorectal origin: a systematic review of national and international guidelines. Color Dis. 2017;19:224-36. https://doi.org/10.1111/codi.13593.

10. Landelijke Werkgroep Gastro Intestinale Tumoren. Richtlijn colorectaal carcinoom Versie 3.0. https://www.nhg.org/sites/defa ult/files/content/nhg_org/uploads/colorectaalcarcinoom.pdf. Accessed 1 Jan 2021.

11. Schmoll HJ, Van Cutsem E, Stein A, et al. Esmo consensus guidelines for management of patients with colon and rectal cancer: a personalized approach to clinical decision-making. Ann Oncol. 2012. https://doi.org/10.1093/annonc/mds236.

12. Rovers KP, Bakkers C, Simkens GAAM, et al. Perioperative systemic therapy and cytoreductive surgery with HIPEC versus upfront cytoreductive surgery with HIPEC alone for isolated resectable colorectal peritoneal metastases: protocol of a multicentre, open-label, parallel-group, phase II-III, random. BMC Cancer. 2019. https://doi.org/10.1186/s12885-019-5545-0. 
13. Van Cutsem E, Cervantes A, Nordlinger B, Arnold D, The ESMO Guidelines Working Group. Metastatic colorectal cancer: ESMO clinical practice guidelines for diagnosis, treatment and followup. Ann Oncol. 2014. doi:https://doi.org/10.1093/annonc/md u260.

14. Pelz JOW, Stojadinovic A, Nissan A, Hohenberger W, Esquivel J. Evaluation of a peritoneal surface disease severity score in patients with colon cancer with peritoneal carcinomatosis. J Surg Oncol. 2009. https://doi.org/10.1002/jso.21169.

15. Rovers KP, Simkens GA, Vissers PA, et al. Survival of patients with colorectal peritoneal metastases is affected by treatment disparities among hospitals of diagnosis: a nationwide population-based study. Eur J Cancer. 2017. https://doi.org/10.1016/j.e jca.2016.12.034.

16. Hentzen JEKR, Rovers KP, Kuipers $H$, et al. Impact of synchronous versus metachronous onset of colorectal peritoneal metastases on survival outcomes after cytoreductive surgery (CRS) with hyperthermic intraperitoneal chemotherapy (HIPEC): a multicenter, retrospective, observational study. Ann Surg Oncol. 2019. https://doi.org/10.1245/s10434-019-07294-y.

17. Lemmens VE, Klaver YL, Verwaal VJ, Rutten HJ, Coebergh JWW, De Hingh IH. Predictors and survival of synchronous peritoneal carcinomatosis of colorectal origin: a population-based study. Int J Cancer. 2011. https://doi.org/10.1002/ijc.25596.

18. Van Gestel YRBM, Thomassen I, Lemmens VEPP, et al. Metachronous peritoneal carcinomatosis after curative treatment of colorectal cancer. Eur J Surg Oncol. 2014. https://doi.org/10.10 16/j.ejso.2013.10.001.
19. Jeffery M, Hickey BE, Hider PN. Follow-up strategies for patients treated for non-metastatic colorectal cancer. Cochrane Database Syst Rev. 2019. https://doi.org/10.1002/14651858.C D002200.pub4.

20. Mokhles S, Macbeth F, Farewell V, et al. Meta-analysis of colorectal cancer follow-up after potentially curative resection. $\mathrm{Br} J$ Surg. 2016. https://doi.org/10.1002/bjs.10233.

21. Van Der Stok EP, Spaander MCW, Grünhagen DJ, Verhoef C, Kuipers EJ. Surveillance after curative treatment for colorectal cancer. Nat Rev Clin Oncol. 2017. https://doi.org/10.1038/nrclin onc.2016.199.

22. Verberne CJ, Zhan Z, Van Den Heuvel E, et al. Intensified follow-up in colorectal cancer patients using frequent carcinoembryonic antigen (CEA) measurements and CEA-triggered imaging: results of the randomized "CEAwatch" trial. Eur J Surg Oncol. 2015. https://doi.org/10.1016/j.ejso.2015.06.008.

23. Verberne CJ, Zhan Z, van den Heuvel ER, et al. Survival analysis of the CEAwatch multicentre clustered randomized trial. $\mathrm{Br} \mathrm{J}$ Surg. 2017. https://doi.org/10.1002/bjs.10535.

24. Elias D, Gilly F, Boutitie F, et al. Peritoneal colorectal carcinomatosis treated with surgery and perioperative intraperitoneal chemotherapy: retrospective analysis of 523 patients from a multicentric French study. J Clin Oncol. 2010. https://doi.org/10. 1200/JCO.2010.29.0163.

Publisher's Note Springer Nature remains neutral with regard to jurisdictional claims in published maps and institutional affiliations. 